\title{
Characterizing carbonate facies using high-definition frequency decomposition: Case study from North West Australia
}

\author{
Mohammed Al-Maghlouth ${ }^{1}$, Peter Szafian², and Rebecca Bell ${ }^{3}$
}

\begin{abstract}
Carbonate facies identification is difficult using conventional seismic attributes due to subtle lithologic changes that cannot be easily recognized. Therefore, there is a need to develop new methodologies to study their evolution and their associated sedimentary processes, which will eventually lead to better prediction for reservoir-quality rocks. New insights into the Cenozoic carbonates in North West Australia have been captured with the application of a high-definition seismic attribute workflow. The workflow starts with conditioning of the seismic volume using structurally oriented noise attenuation filters to remove any random and coherent noise from the input data. It also benefits from a high-definition frequency decomposition that matches the original seismic resolution without smearing interfaces using a "matching pursuit" algorithm. A color blend of multigeometric attributes, such as semblance and conformance, has also been used in the workflow to define edges and discontinuities present in the data within carbonate deposits that are attributed to depositional geometries, such as barrier reefs. Our workflow has been developed to investigate the geomorphology and the sedimentary processes affecting Cenozoic successions in the Northern Carnarvon Basin in North West Australia. Geomorphological and sedimentological observations have been documented such as an Eocene rounded carbonate ramp with evidence of slump blocks and scarps, Middle Miocene accretions generated due to longshore drift, and the presence of Pliocene-Pleistocene patch and barrier reefs. These observations were extracted as geobodies to allow for visualization, and they can be used in an automated seismically based facies classification scheme. The new appreciations are not only useful for understanding the carbonate evolution but can also be used to identify geohazards such as slumps ahead of future drilling.
\end{abstract}

\section{Introduction}

Since the introduction of seismic attributes to the petroleum industry in the early 1970 s, seismic attribute analysis has played an important role in the exploration and development workflow, allowing reservoir and fluid properties to be detected and reducing uncertainties in resource estimations (Chopra and Marfurt, 2005, 2007). A common task for the interpreter is to predict and differentiate reservoir facies. This can be easily done in clastic settings in which rock-physics theories allow for better identification of sand against shale facies (Meldahl et al., 2001; Chopra and Pruden, 2003; Avseth et al., 2005). In contrast, carbonate rocks have physical characteristics that make predicting how they will be observed with various seismic attributes challenging, such as lateral heterogeneity in porosity type and distribution, subtle facies change, velocity dispersion, and attenuation due to complex rock framework, permeability heterogeneity, and susceptibility to early diagenesis (Vanorio et al., 2012). All of these challenges make attribute analysis and rock-physics theories difficult to apply in carbonates (Vanorio et al., 2012). Previous studies, such as that by Hong and Shipilova (2013), suggest that the use of multiattribute analysis and neural networks could illuminate carbonate buildups and reveal subtle stratigraphic features, such as reef buildups, shoal beaches, and progradational patterns from seismic reflection data. This is because the integration of several types of information provided by multiattribute analysis and calibration of neural networks, which starts with well logs and core measurements, provide a better prediction for carbonate facies identification.

We present a new seismic attribute workflow, which benefits from a high lateral and vertical resolution, matching the original seismic resolution, to allow for a fast and efficient definition of the 3D morphology of geologic features that can be tailored to detect carbonate features. The backbone of this workflow is clean and conditioned data to increase the productivity of

${ }^{1}$ Formerly Imperial College, London, UK; presently Saudi Aramco, Dhahran, Saudi Arabia. E-mail: ma614@ic.ac.uk.

${ }^{2}$ GeoTeric, London, UK. E-mail: peter.szafian@geoteric.com.

${ }^{3}$ Imperial College, London, UK. E-mail: rebecca.bell@imperial.ac.uk.

Manuscript received by the Editor 1 October 2016; revised manuscript received 12 December 2016; published online 21 June 2017. This paper appears in Interpretation, Vol. 5, No. 3 (August 2017); p. SJ49-SJ59, 13 FIGS.

http://dx.doi.org/10.1190/INT-2016-0173.1. @ 2017 Society of Exploration Geophysicists and American Association of Petroleum Geologists. All rights reserved. 
subsequent processes. The workflow is tested on the Cenozoic carbonate sequences in the Northern Carnarvon Basin in North West Australia. Although previous studies have identified the carbonate facies distribution in the basin, the result of this analysis allows for 3D visualization of the geomorphology of cool-water nontropical carbonate factories and how they evolve into a shallow-water tropical carbonate platform over time. In addition, the role of siliciclastic influx that took place in the Middle Miocene and its impact to the paleoshoreline is investigated.

\section{Geologic setting}

The study area is located in the Northern Carnarvon Basin in North West Australia (Figure 1). The basin is part of several Paleozoic to Cenozoic subbasins forming the northwestern continental margin of Australia (Apthorpe, 1988). It is filled by more than $15,000 \mathrm{~m}$ of deltaic to marine siliciclastic and shelfal carbonates of Mesozoic to Cenozoic age (Bradshaw et al., 1998). The Demeter 3D seismic reflection survey, which was shot in 2005, has been chosen to evaluate the workflow. The survey is located in the Dampier subbasin within the Northern Carnarvon Basin, which benefits from several sequences of tropical and nontropical carbonate deposits as suggested by several well penetrations in the basin (Cathro, 2002; Sanchez, 2011). Unfortunately, well-log data were not available for this project.

During the mid-Santonian, the Northern Carnarvon basin became tectonically stable and experienced a longterm warm and arid climate as it moved northward from approximately $40^{\circ} \mathrm{S}$ to $20^{\circ} \mathrm{S}$ (Apthorpe, 1988; McGowran et al., 1997). The tectonic stability and climate resulted in a transition from a mostly siliciclastic succession during the Mesozoic to a predominantly carbonate sedimentation since the Eocene (Apthorpe, 1988; Butcher, 1989) (Figure 2).
Cool-water nontropical carbonate sedimentation was the dominant carbonate factory during the Late Paleocene to Early-Middle Miocene when siliciclastic influx overtook carbonate deposition (McGowran et al., 1997; Gokstas, 2013). During a period of long-term global sealevel fall, shelfal and shelf edge deltas prograded across the carbonate shelf (Apthorpe, 1988). The accumulated delta lobes, along with a climatic shift, created favorable conditions for the growth of tropical shallow-water car-

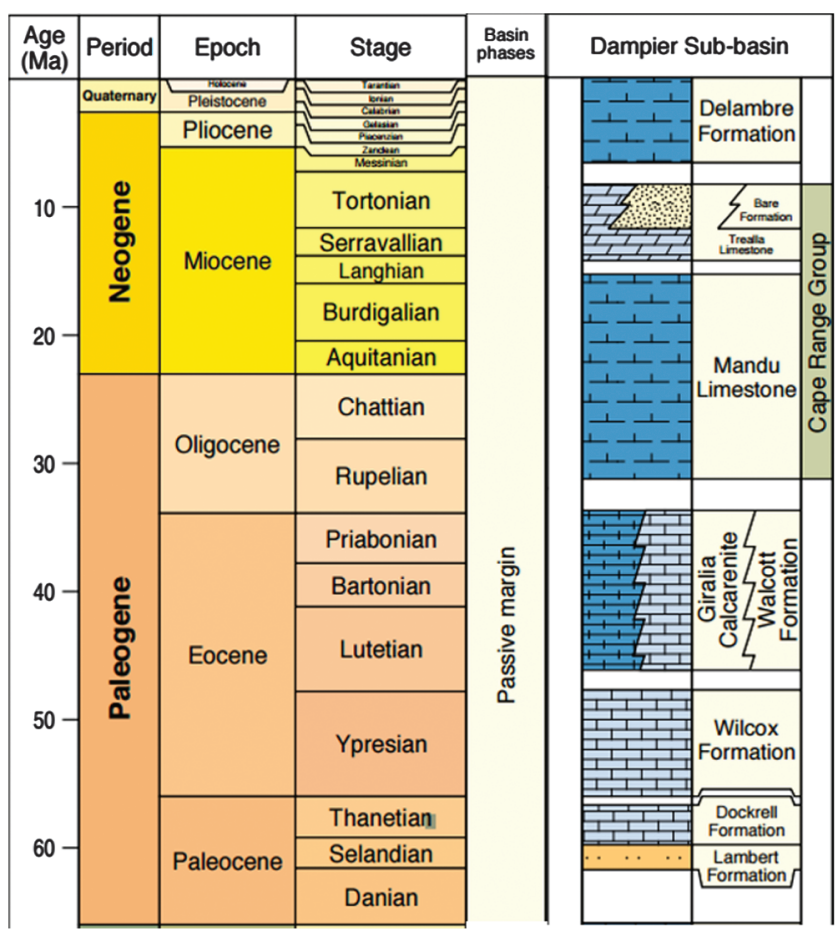

Figure 2. Stratigraphic chart of the Cenozoic sequence covering the Paleogene and Neogene periods.

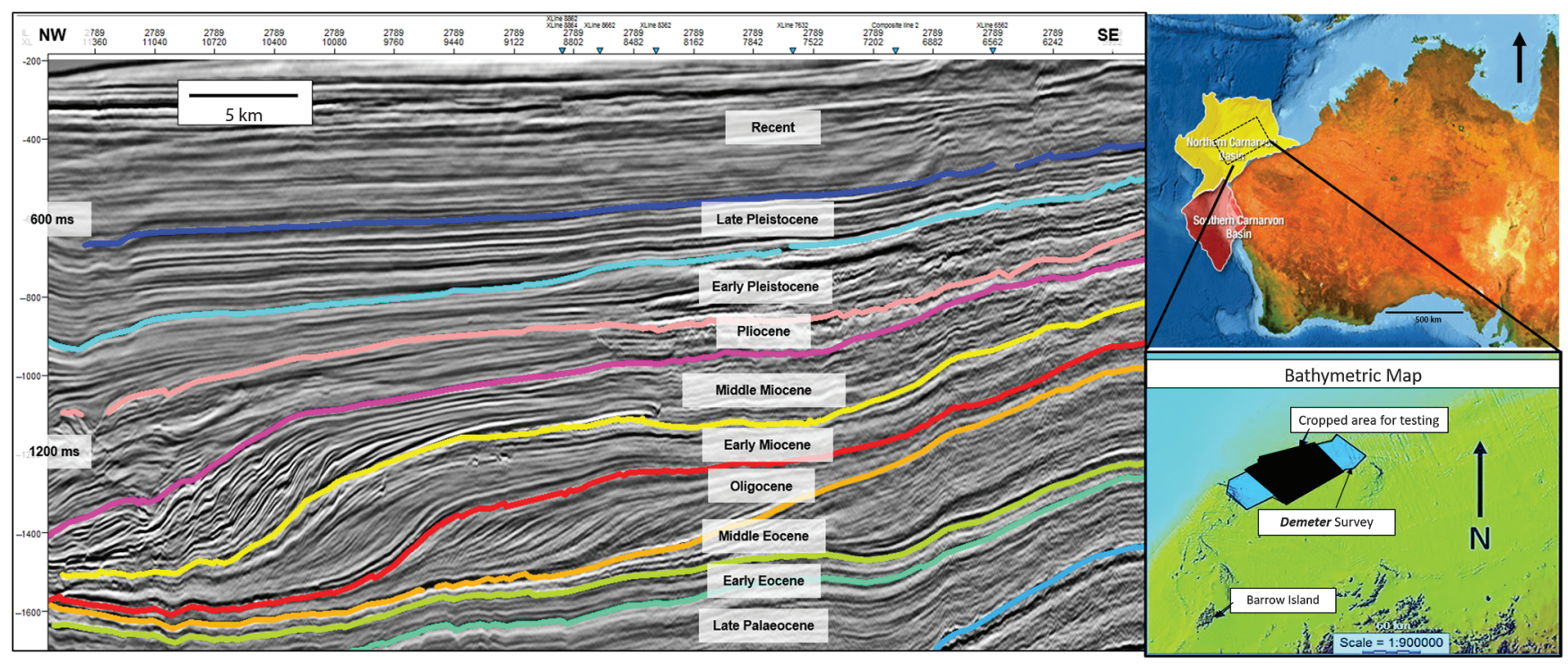

Figure 1. The Demeter survey location within the Northern Carnarvon Basin in North West Australia and an interpreted seismic line showing the Cenozoic sequences. 
bonate in the Pliocene (Cathro, 2002; Sanchez, 2011; Gokstas, 2013). Although studies by Cathro et al. (2003), Wallace et al. (2003), and Sanchez et al. (2012) constrained the main facies distribution of carbonate evolution and the influence of the siliciclastic influx during the Late Miocene, the large-scale 3D morphology and the localized sedimentary processes that are key in understanding the paleoenvironment have not been considered in their interpretation.

\section{High-definition seismic attribute workflow}

We used a high-definition seismic attribute workflow, benefiting from fast algorithms, to allow for better visualization and automated facies classification. The workflow starts with data conditioning followed by multiattribute computation and automated facies classification to allow for data-driven and interpreter-guided analysis. Although we believe that the workflow is applicable to any data set, we used the Demeter 3D survey because it benefits from imaging extensive carbonate sequences. The Demeter 3D survey covers almost $3550 \mathrm{~km}^{2}$. The survey was shot in April 2003 and completed after processing in January 2005. It was acquired using ten $5 \mathrm{~km}$ long streamers, $50 \mathrm{~m}$ apart, with a single source gun. The nominal fold was 133 with a record length of $6 \mathrm{~s}$ and sampling interval of $2 \mathrm{~ms}$. The depth of the source was $5 \mathrm{~m}$, and the receiver was $6 \mathrm{~m}$ in depth. The bin size was $6.25 \times 25 \mathrm{~m}$. Extensive demultiple processing and velocity analysis were essential in delivering a high-quality seismic volume (Bennett and Bussell, 2006).

\section{Data conditioning}

Noise cancellation

Most noise suppression is performed during seismic data processing in the prestack domain. However, coherent and random noise can still be present in the stacked seismic data, overprinting geologic information and subsequently affecting the interpretation. To minimize noise in the seismic data, two stages of noise attenuation were applied. The first stage targeted the coherent noise in the data using a structurally oriented, edge-preserving, finite-impulse-response, median hybrid filter (Heinonen and Neuvo, 1987; Nieminen et al., 1987; Astola et al., 1989). The second stage aimed at removing remnant random noise through iterative application of an edge-adaptive anisotropic tensor diffusion filter (after Perona and Malik, 1990). Using either dip and azimuth volumes or internal steering algorithms to guide these filters along the seismic reflections, we can ensure that edges, trends, and details that are critical for detecting subtle stratigraphic features are preserved.

\section{Spectral enhancement}

The vertical resolution and localization power of a seismic data set is a function of the bandwidth of the signal. Spectral enhancement aims at increasing the bandwidth of the data set by selectively boosting portions of the seismic signal with distinguishable frequency content
(McArdle and Paton, 2014). Enhancing the high end of the frequency spectrum allows for better imaging of thin beds and provides better continuity and interpretability of the data. Even though the interpretability of the data has improved, this method should be applied with caution and only after the noise attenuation to avoid boosting the noise. Because it is difficult to differentiate signal from noise, a visual examination should always be made when dealing with spectral enhancement tools. Figure 3a shows the original and enhanced spectra, demonstrating the improvement especially at high frequencies. Figure $3 \mathrm{~b}$ and $3 \mathrm{c}$ illustrates how the data conditioning steps attenuate the coherent, steeply dipping noise and improve the continuity and interpretability of seismic events.

\section{Attributes computation \\ Geometric attributes}

There is a range of geometric attributes that can help in revealing the seismic texture and detecting subtle edges such as channels and depositional geometries (for a summary, see Chopra and Marfurt, 2007). In this study, three different attributes were used. The first one is a structurally oriented semblance, whereby calculations are performed along reflections (Chopra and Marfurt, 2007). This attribute is sensitive to phase breaks or sharp changes in the waveform. In the calculated attribute, high values represent discontinuities and low values represent areas of uniformity (Figure 4a). The second attribute is conformance (developed by GeoTeric), which is a structurally oriented measure of the degree of deviation from the local dominant orientation at each voxel of the seismic volume. The attribute uses precalculated dip and azimuth volumes: High conformance values represent stable reflectors, and low conformance values represent areas of variability (Figure $4 \mathrm{~b}$ ). The third geometric attribute used in this analysis is 3D dip to highlight steeply dipping zones in the data (Figure 4c).

\section{Frequency decomposition}

Frequency decomposition was first introduced to the seismic interpretation workflow. In the past 15 years, the method has become a standard application, and now all major seismic interpretation software systems offer different versions of it. All of these versions, including Fourier transformation, continuous wavelet transformation, or matching pursuit decomposition, have their advantages and disadvantages, and the selection depends on the objectives of the workflow.

In this study, a modified-matching-pursuit-based algorithm was used (see Mallat and Zhang, 1993; Szafian et al., 2015) because it offers the highest possible vertical (temporal) resolution and localization of seismic events. The method relies on a predefined, dynamic library of Gabor wavelets at different frequencies and phase rotations, which are iteratively matched to the seismic trace according to the highest spectral energy, thus reconstructing it, without windowing or vertical smearing (Figure 5). Because there are no well logs 
available in this study, we use a visual examination to set the red-green-blue (RGB) color blend. To achieve the best differentiation of the analyzed geologic features, a series of frequency responses and their combinations are analyzed in an interactive, iterative manner. Once the best frequencies for the RGB blend are selected (26, 40, and $50 \mathrm{~Hz}$ in this case), the corresponding band-limited frequency response magnitude volumes can be calculated from the wavelet sets of the reconstructed traces.

\section{Visualization and corendering}

Even though vertical and lateral seismic resolutions are important, the color resolution and how we perceive colors add significant value to our interpretation (Froner et al., 2013). The nonlinearity of the human vis-

a)

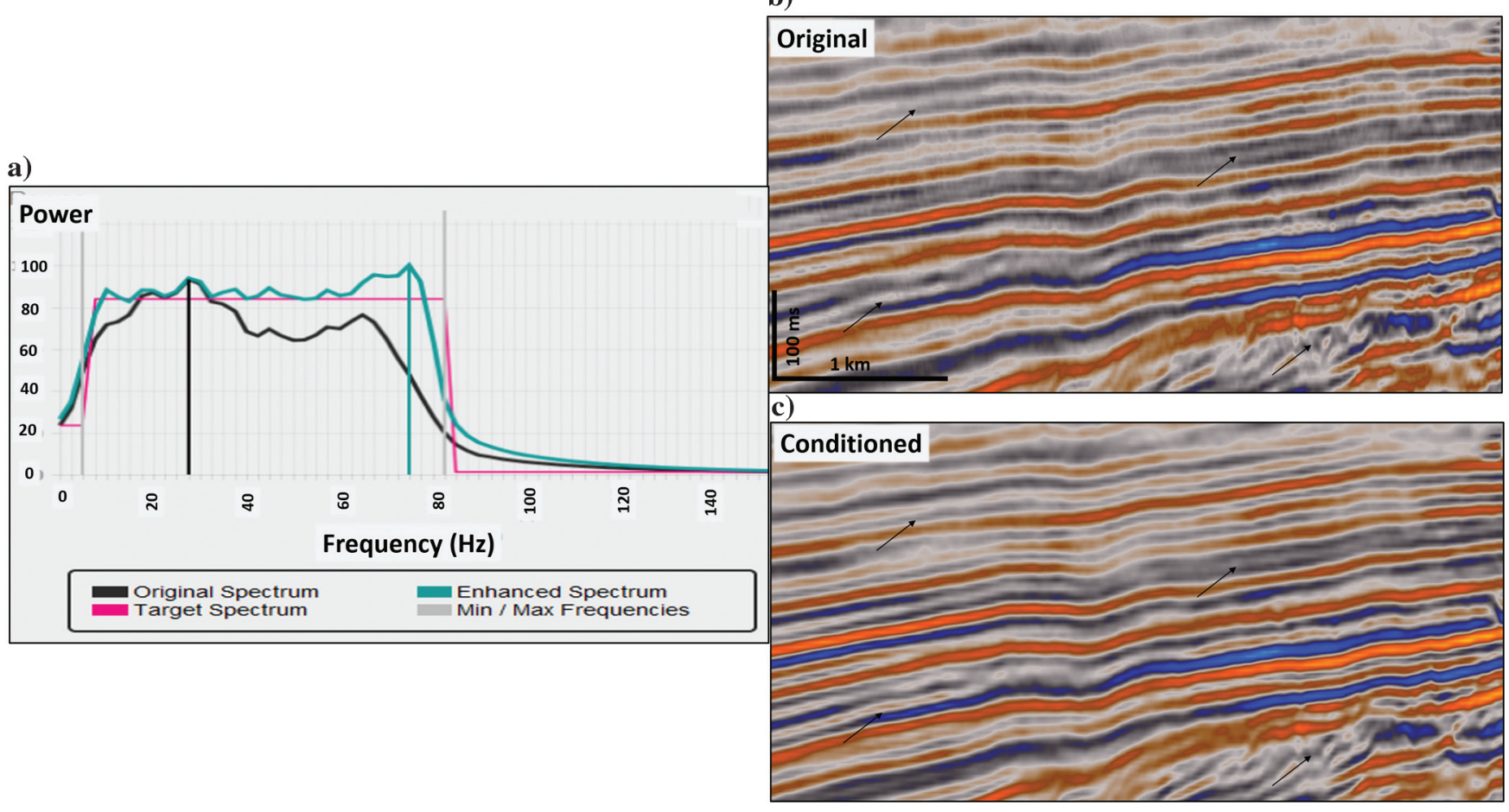

b)

Figure 3. (a) Amplitude spectrum before and after spectral enhancement. (b) Original seismic data. (c) Conditioned seismic data showing more continuous reflections after noise attenuation and spectral enhancement. The arrows point to areas of improved interpretability.

a)

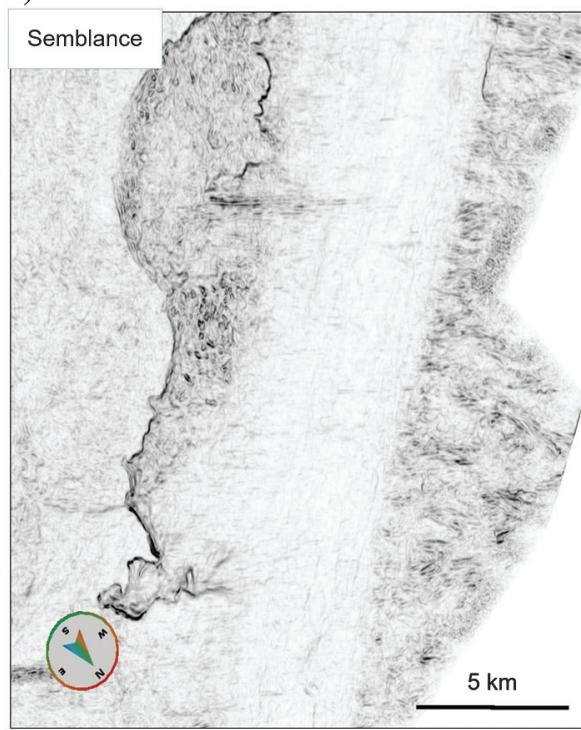

b)

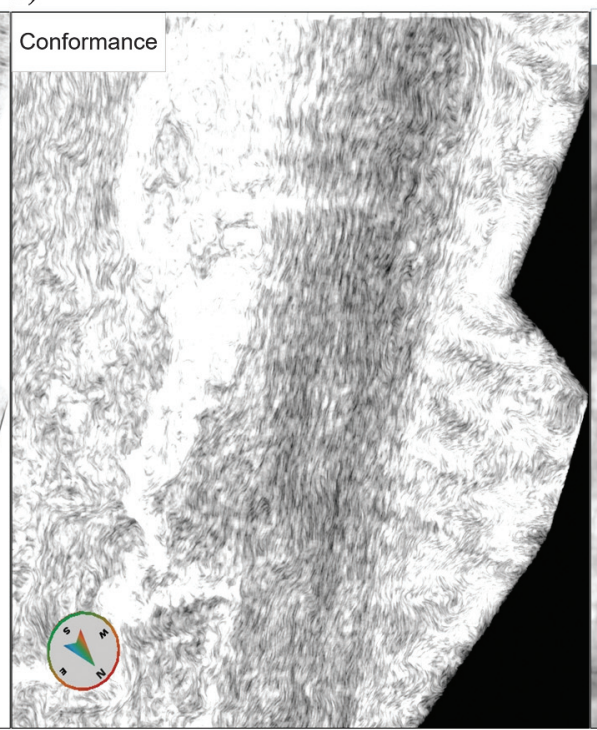

c)

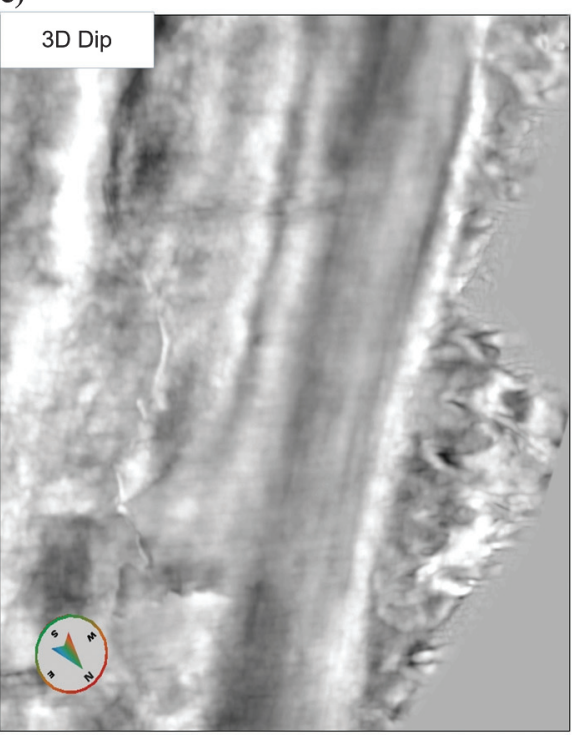

Figure 4. (a) Semblance seismic attribute; (b) conformance seismic attribute; (c) 3D dip attribute. 
ual system leads to the possibility of interpretations being based not on actual features that are present in the data but on illusions created by false perceptions. To avoid this, new techniques have been introduced to visualize information in a way that is perceptually in tune with the human visual system (Stark, 2006; Froner et al., 2013). Furthermore, these techniques enable us to use explicit encoding to represent and simultaneously analyze different pieces of information and their relationship (Paton and Henderson, 2015). The most frequently used type of explicit encoding is color blending, whereby three attributes are corendered using different color schemes. In this paper, we use RGB and cyan-magenta-yellow (CMY) color blends. The first is an additive color model, in which three equally strong signals on the three color channels result in a white response, whereas the latter is a subtractive color model; i.e., three strong responses result in a black response. The RGB and CMY color models can be used for a variety of attributes. It is preferable, based on experience, to use the RGB model to mix frequency magnitude volumes (Figure 6). The CMY model can be used to blend geometric attributes to highlight faults, fractures, and channel edges (Henderson et al., 2007; Guo et al., 2008; Purves and Basford, 2011). The CMY color blend presented in this study shows that conformance and semblance attributes dominate with no major contribution from the dip attribute. As shown in Figure 7, edges and discontinuities in the blend are represented as cyan and purple colors.

\section{Results and interpretation}

The Demeter survey was chosen particularly to apply the workflow because it exhibits a dynamic transition from nontropical carbonate platform to warm tropical carbonate production (Apthorpe, 1988; Gokstas, 2013). The challenge in this data set is to investigate the geomorphological and sedimentological processes em-

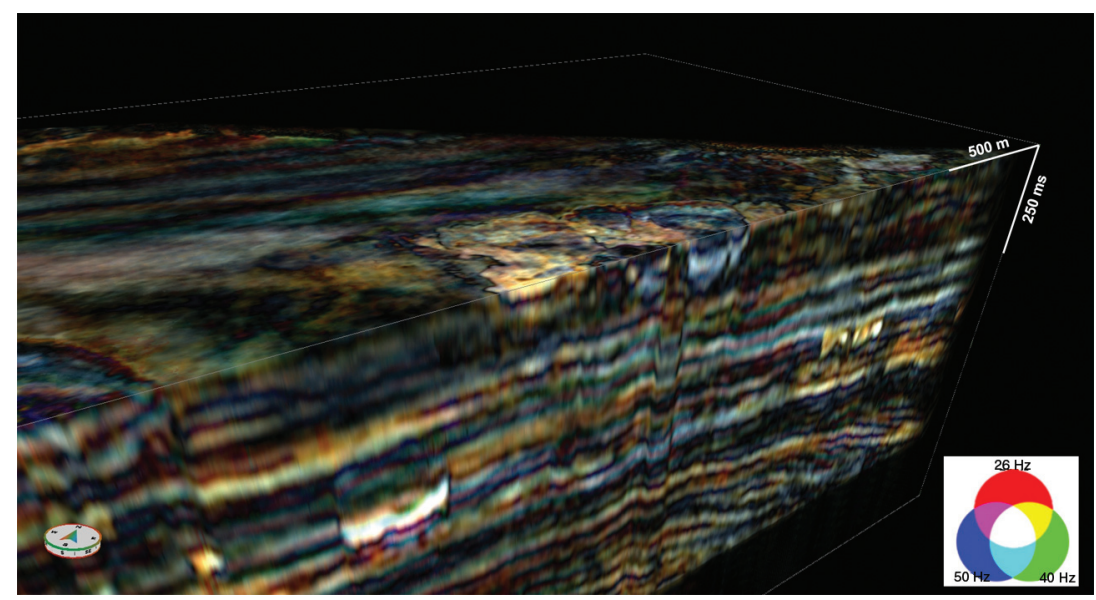

Figure 5. Color blend of three frequency magnitude volumes (26, 40, and $50 \mathrm{~Hz})$.

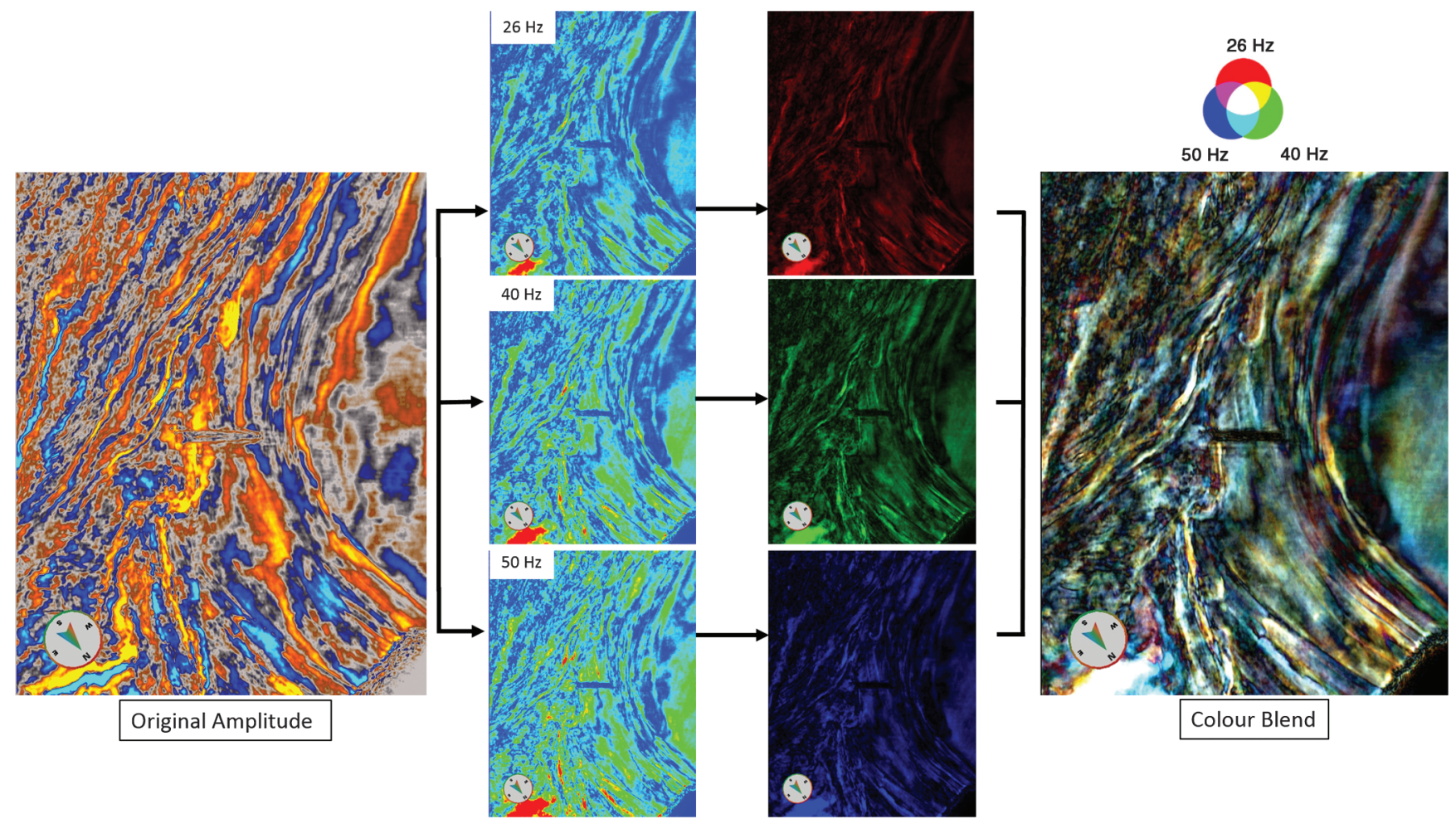

Figure 6. An RGB color blend of frequency volumes starts with transforming the color spectrum of the frequency volumes to red, green, and blue before mixing. 
bedded in the seismic data, which have not previously been revealed. The workflow was applied to a portion of the Demeter survey $(60 \times 60 \mathrm{~km})$ in a time interval between 400 and $1800 \mathrm{~ms}$, as shown in Figures 1 and 2 , to accelerate the computation process without missing geologic features. We produced an RGB color blend of three frequency magnitude volumes $(26,40$, and $50 \mathrm{~Hz}$ ). In addition, a CMY blend of geometric attributes (conformance, semblance, and dip) was also used. The successful implementation of multiattribute analysis revealed interesting, previously undiscovered, geomorphological, and sedimentological processes that can be calibrated to build a conceptual geologic model of the carbonate growth during the Cenozoic in North West Australia. Due to the unavailability of well logs in this study, most of the observations are based on calibration of the seismic attribute observations with drilling reports and ditch cuttings. Previous studies from Cathro (2002), Sanchez (2011), and Gokstas (2013) are integral in constraining the age and controlling the horizon interpretation.

\section{The nontropical Oligocene carbonate ramp}

A 3D dip attribute horizon slice from the Oligocene Red Horizon in Figure 1 reveals a featureless margin with no significant edges or discontinuities observed, apart from channelized slope gullies (Figure 8). This horizon slice, which covers the Oligocene to Early Miocene as suggested by Cathro (2002) and Cathro et al. (2003), in- dicates a nontropical carbonate ramp with no significant clastic incision as shown in Figure 8 confirming their analysis of stable carbonate production in the Oligocene. However, an RGB color-blend horizon slice of the Early Miocene Yellow Horizon exposes erosional processes within the shelf with an abrupt increase in the amplitude and frequency content. The high-definition frequency decomposition allows for better illumination of geomorphological processes (Figure 9). Based on the chaotic nature associated with abrupt change in frequency content, we interpreted this feature as a headscarp with associated slumping facies, similar to the geologic features that have been observed in California (Figure 9) (USGS, 2004).

\section{The mixed siliciclastic-carbonate setting of the Middle Miocene}

An RGB color-blend horizon slice of the Middle Miocene Purple Horizon (seismic TWT 800 to $1500 \mathrm{~ms}$ ) shows previously undiscovered lineations that are prograding to the north (Figure 10). Based on lithologic observations from several wells, Cathro (2002) interprets this interval as the onset of the clastic influx suggesting these lineations to be longshore accretion surfaces because the sediments are transported along the shore due to swash and backwash movements. Detailed mapping of these accretions will enable a high-resolution sequence stratigraphic framework of the sand deposits to be developed. This horizon slice also reveals a lobate

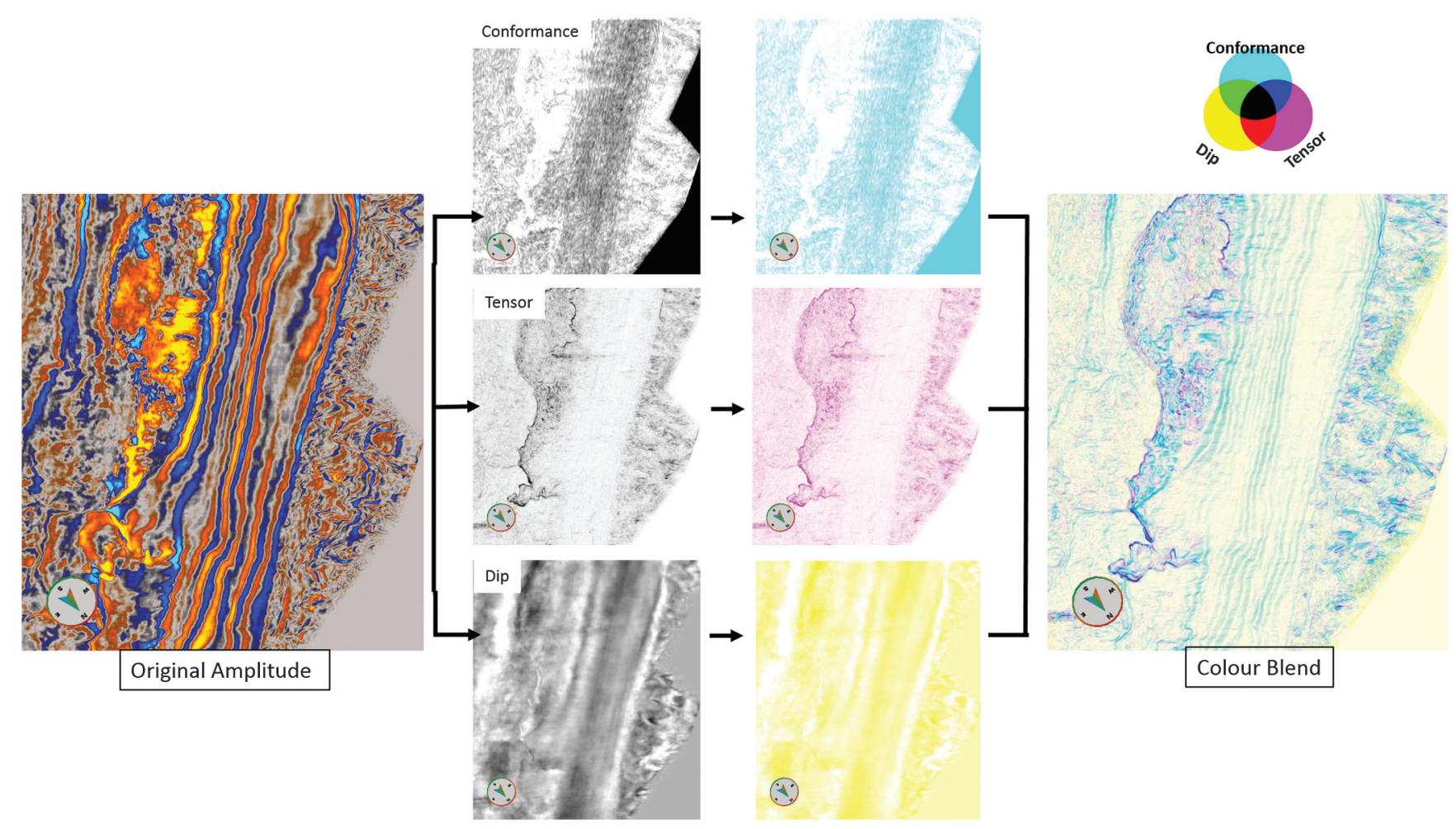

Figure 7. A CMY color blend of geometric attributes starts with transforming the gray scale of the volumes to cyan, magenta, and yellow before mixing. 
to arcuate feature that is interpreted here as a paleoshoreline, which is expressed as a strong white response (indicating high-frequency magnitude in the decomposed volumes) that has prograded for at least $1 \mathrm{~km}$ to the northwest (Figure 10).

\section{The tropical carbonate platform in the Pleistocene}

The RGB color-blend horizon slice of the Pliocene Pink horizon, which marks the beginning of the tropical carbonate platform as suggested by Gokstas (2013) and Cathro (2002), shows linear features that extend for sev-

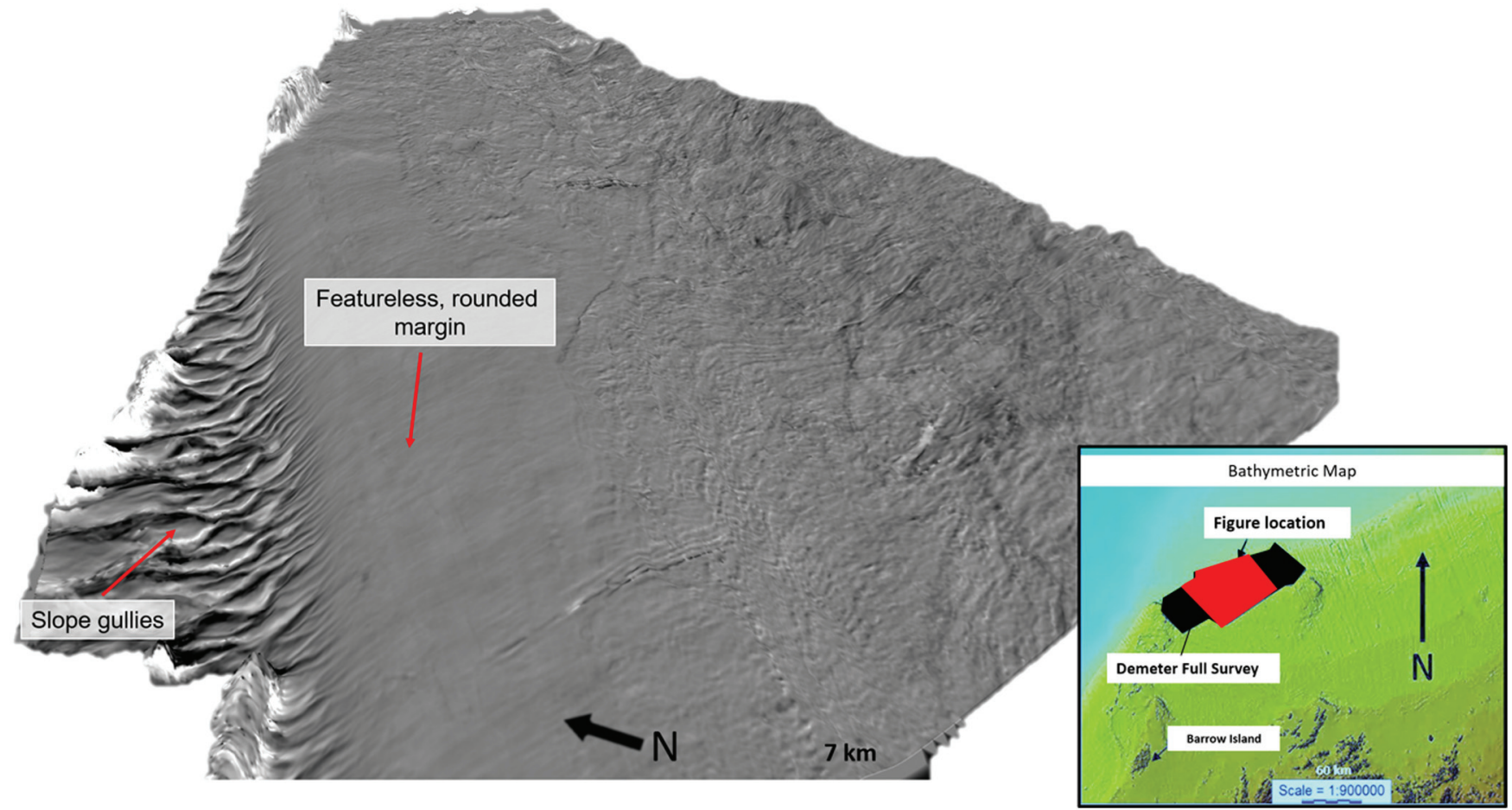

Figure 8. A 3D dip attribute horizon slice from the Oligocene to Early Miocene interval showing nontropical carbonate ramp with a featureless, rounded margin, and slop gullies downdip.

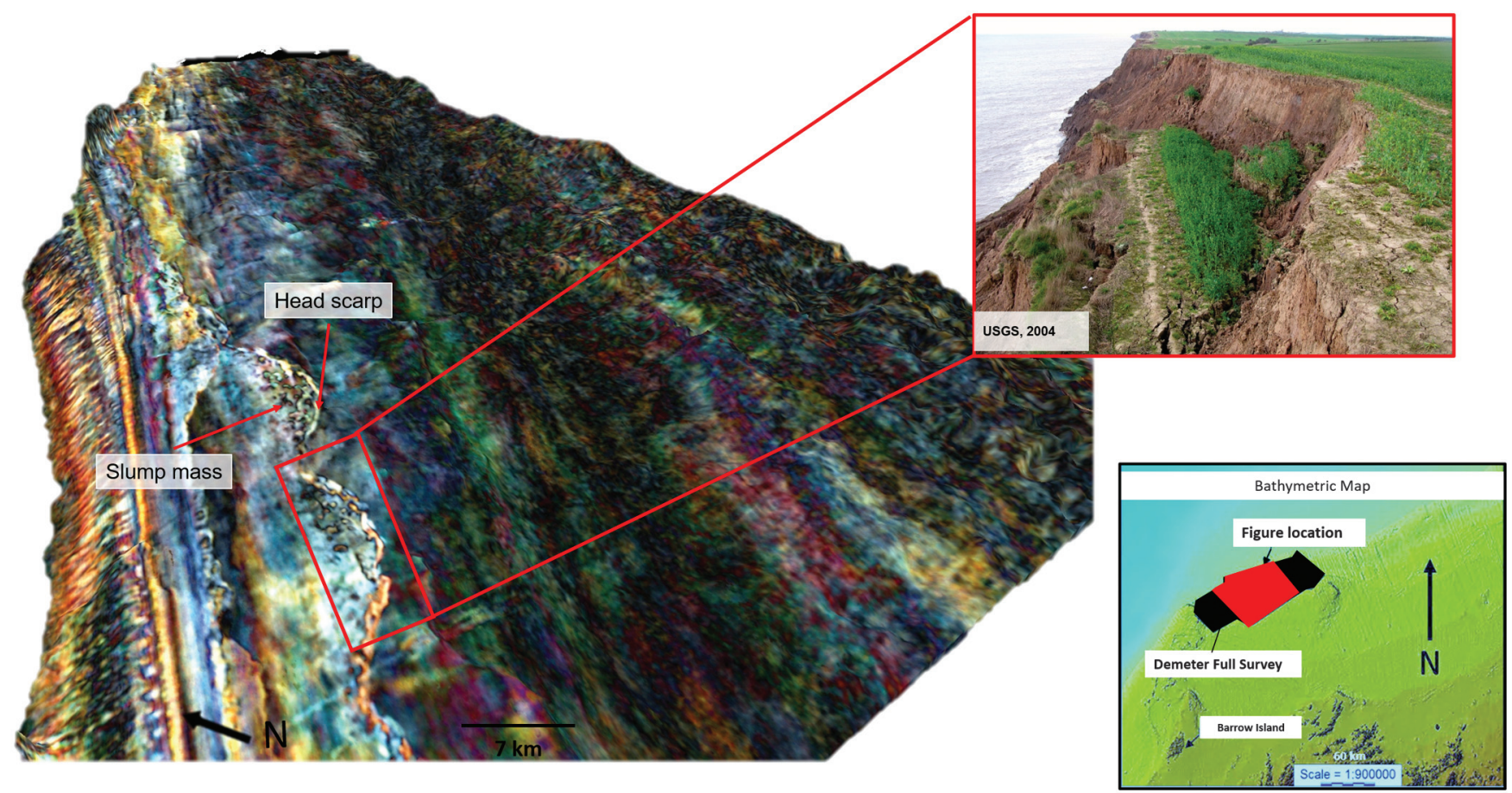

Figure 9. An RGB color-blend horizon slice from the Oligocene to Early Miocene showing abrupt changes in the frequency response attributed to head scarp and slump mass activity. 
eral tens of kilometers and have a curved morphology (Figure 11). Along with this observation, 3-4 km wide patches with a high-frequency response have been identified. When we correlate these observations with a modern carbonate platform such as the Belize Reef (Loucks et al., 2003), we were able to interpret the linear features as a prograding barrier reef, whereas the patchy strong response we interpret as a platform interior with patch reefs. The size of the Belize patch reefs is almost similar to the ones observed in the data set (3-4 km wide).

A close-up slice within the carbonate platform using the CMY blend, which mixes geometric attributes (con-

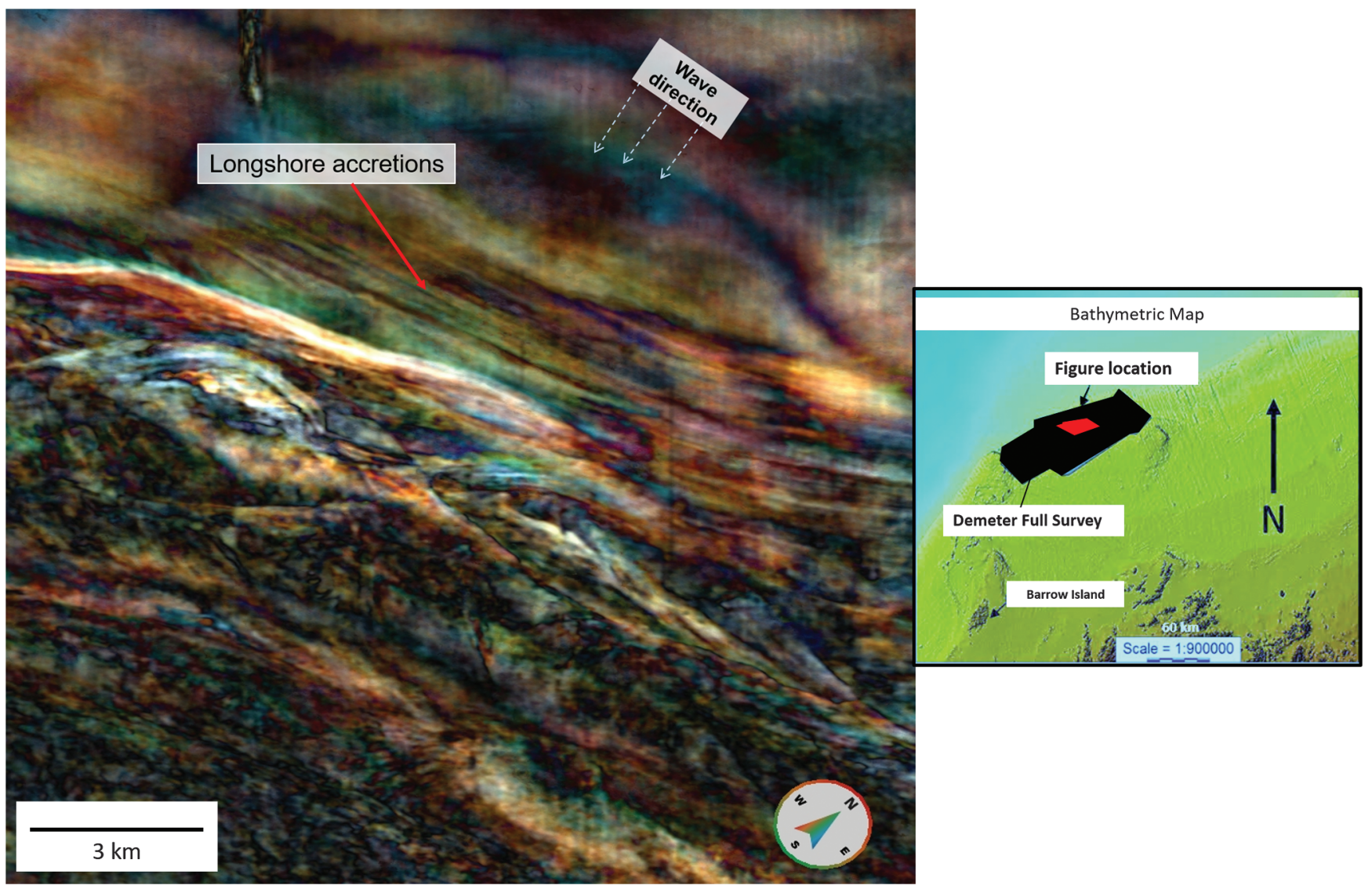

Figure 10. An RGB color-blend horizon slice from the middle Miocene interval showing lineations parallel to the paleoshoreline, which were interpreted as longshore accretion surfaces.
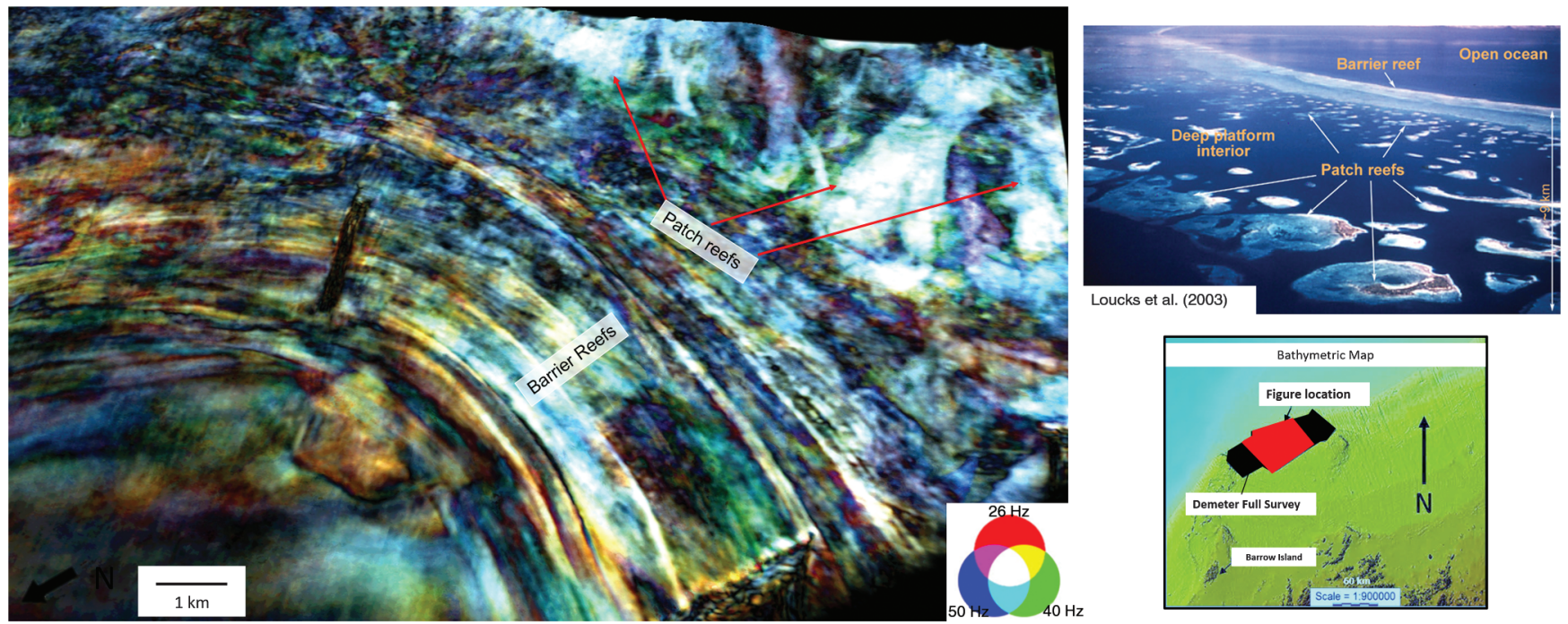

Figure 11. An RGB color-blend horizon slice from the Pleistocene carbonate platform showing curved morphology and patchy strong responses shallower in the section. 
formance, semblance, and dip), shows previously unidentified, small (less than $100 \mathrm{~m}$ wide) concave, and overlapping ridges migrating to the west (Figure 12). The length of the individual ridge is between 0.5 and $2.5 \mathrm{~km}$. These features are interpreted as interior platform sand shoals deposited as a result of wave action across the shelf. The movement of these ridges across the platform is mainly dominated by the strength and direction of the waves.

\section{Interactive facies classification}

In its basic definition, a seismic geobody is an interpreted 3D object that contains cells (or voxels) with similar seismic characteristics (Chopra and Marfurt, 2007). It is an emerging tool to visualize and extract geologic features in a volumetric sense, using multiple seismic attribute volumes or a combined volume. The ability to discriminate zones of interest when choosing the optimum seismic attribute is vital for geobody interpretation and extraction.

In Figure 13a, a seismic feature has been identified with various frequency response indicating lateral changes in facies. Without doing any further processes, this RGB color blend was used as an input for interactive facies classification to automatically extract geobodies and to classify them based on color recognition (Figure 13b). The different facies were defined by selecting different sample areas along horizons and sections. Using the values within the sample areas, Gaussian mixture models with unit-area normalization were calculated. In the next step, all voxels in the volume were analyzed and were either classified into one of the facies or left unclas-
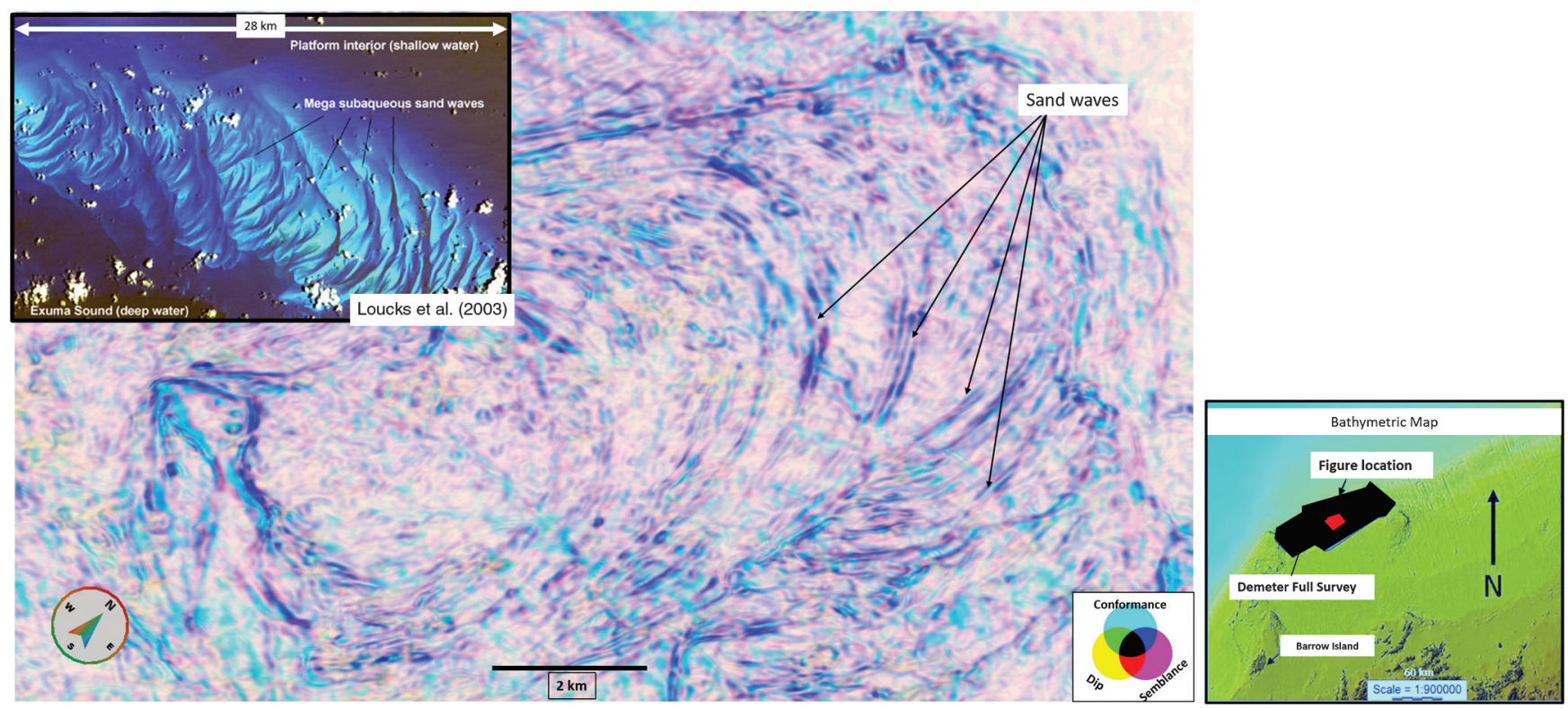

Figure 12. A CMY color-blend horizon slice showing small concave-upward overlapping ridges migrating to the northwest.

a)

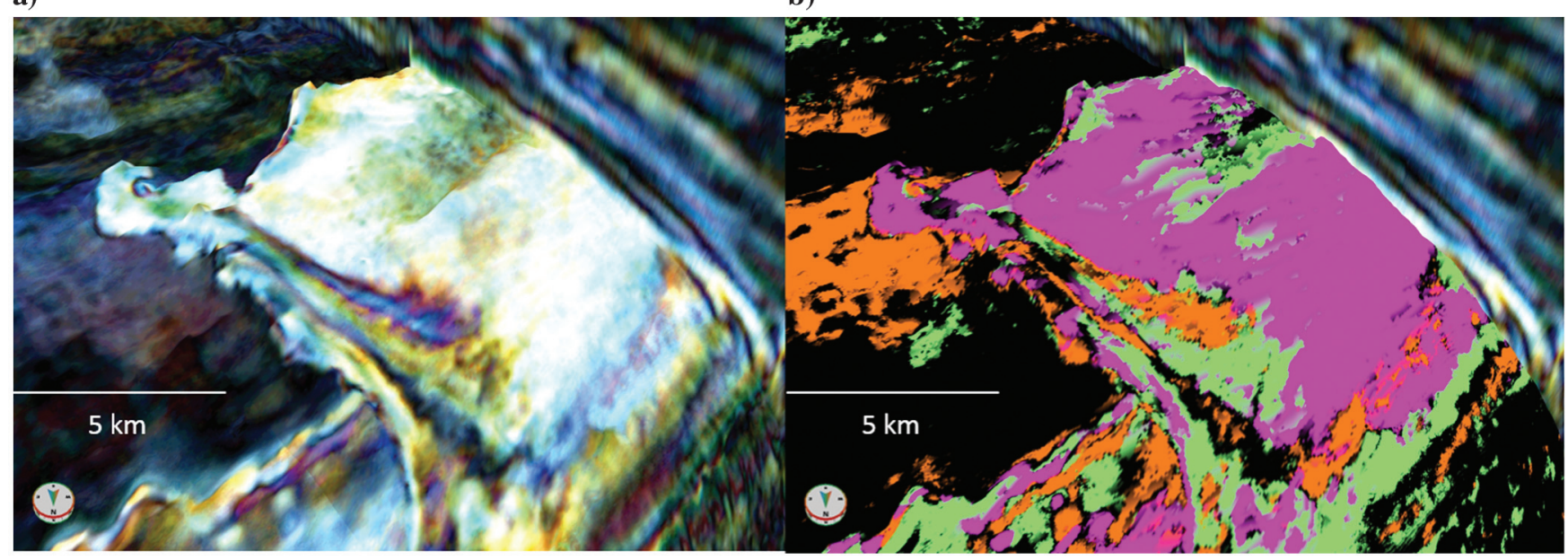

Figure 13. (a) An RGB color blend showing a geologic feature. (b) Interactive facies classification based on frequency signature from the RGB color-blend volume. 
sified. The algorithm applies a hierarchical clustering method to identify subfacies that are not immediately obvious for the interpreter. In Figure 13b, three main classifications have been automatically generated, distinguishing the characteristic frequency response that corresponds to three different facies in this seismic feature. This interactive facies classification can be extended to several layers and horizons to convert the seismic data to a 3D geologic model incorporating the lateral and vertical changes in the facies.

\section{Conclusion}

The use of an RGB color blend, which mixes highdefinition frequency magnitude volumes using matching pursuit algorithm, allows for better carbonate facies identification and superior illumination of geomorphological and sedimentological observations that have not been previously identified in the Northern Carnarvon Basin. In addition, the CMY blend, which mixes geometric attributes, is a breakthrough in delivering a single volume with covariant information. Both blends can provide a geologically feasible interactive facies classification, which helps in building a 3D geologic model of the Cenozoic carbonate evolution in the Northern Carnarvon Basin.

\section{Acknowledgments}

The authors would like to express their sincere gratitude to GeoTeric management for providing the opportunity to use the GeoTeric software and for their continuous support and encouragement. Also their appreciation goes to Saudi Aramco management for their generous sponsorship of the postgraduate program at Imperial College where this study was performed. In addition, the authors would like to acknowledge the reviewers of Interpretation and D. Johnston, the editor of this paper, for his valuable recommendations and kind help.

\section{References}

Apthorpe, M., 1988, Cainozoic depositional history of the North West Shelf, in P. G. Purcell, and R. R. Purcell, eds., The North West Shelf Australia: Petroleum Exploration Society Symposium, 55-88.

Astola, J., P. Heinonen, and Y. Neuvo, 1989, Linear median hybrid filters: IEEE Transactions on Circuits and Systems, 36, 1430-1438, doi: 10.1109/31.41299.

Avseth, P., T. Mukerji, and G. Mavko, 2005, Quantitative seismic interpretation: Applying rock physics tools to reduce interpretation risk: Cambridge University Press.

Bennett, K. J., and M. R. Bussell, 2006, Demeter high resolution 3D seismic survey: Revitalised development and exploration on the North West Shelf, Australia: The APPEA Journal, 46, 101-126.

Bradshaw, M. T., G. D. Karner, J. Kaldi, L. Newman, and L. B. Collins, 1998, Carbonate clinoforms on Australia's North West Shelf: A key link in global Neogene sea-level history: Australian Geological Survey Organization.
Butcher, B., 1989, Northwest shelf of Australia, in J. D. Edwards, and P. A. Santogrossi, eds., Divergent/passive margin basins: AAPG memoir 48, 81-115.

Cathro, D. L., 2002, Three-dimensional stratal development of carbonate-siliciclastic sedimentary regime, Northern Carnarvon Basin, Northwest Australia: Ph.D. thesis, The University of Texas at Austin.

Cathro, D. L., J. A. Austin, and G. D. Moss, 2003, Prograding along a deeply submerged Oligocene-Miocene heterzoan carbonate shelf: How sensitive are clinoforms to sea level variations?: AAPG Bulletin, 87, 1547-1574, doi: $10.1306 / 05210300177$.

Chopra, S., and K. J. Marfurt, 2005, Seismic attributes - A historical perspective: Geophysics, 70, no. 5, 3SO28SO, doi: 10.1190/1.2098670.

Chopra, S., and K. J. Marfurt, 2007, Seismic attributes for prospect identification and reservoir characterization: SEG.

Chopra, S., and D. Pruden, 2003, Multiattribute seismic analysis on AVO-derived parameters: The Leading Edge, 22, 998-1002, doi: 10.1190/1.1623640.

Froner, B., S. J. Purves, J. Lowell, and J. Henderson, 2013, Perception of visual information: The role of colour in seismic interpretation: First Break, 31, 29-34, doi: 10 .3997/1365-2397.2013010.

Gokstas, D. L., 2013, Morphologies and controls on development of Pliocene-Pleistocene carbonate platforms: Northern Carnarvon Basin, Northwest Shelf of Australia: M.S. thesis, The University of Texas at Austin.

Guo, H., S. Lewis, and K. J. Marfurt, 2008, Mapping multiple attributes to three- and four-component color models A tutorial: Geophysics, 73, no. 3, W7-W19, doi: 10.1190/ 1.2903819 .

Heinonen, P., and Y. Neuvo, 1987, FIR-median hybrid filters: IEEE Transactions on Acoustics, Speech, and Signal Processing, 35, 832-838, doi: 10.1109/TASSP.1987 .1165198.

Henderson, J., S. J. Purves, and C. Leppard, 2007, Automated delineation of geological elements from 3D seismic data through analysis of multichannel, volumetric spectral decomposition data: First Break, 25, 87-93.

Hong, F., and E. Shipilova, 2013, Seismic attribute mapping in carbonate depositional environment: Some lessons from case studies: Presented at the Annual Convention and Exhibition, AAPG.

Loucks, R., S. Rodgers, C. Kerans, and X. Janson, 2003, Platform-interior carbonate depositional environments, http://www.beg.utexas.edu//mod/_IOL-CM02/cm02start01.htm, accessed 28 June 2015.

Mallat, S., and Z. Zhang, 1993, Matching pursuit with timefrequency dictionaries: IEEE Transactions and Signal Processing, 41, 3397-3415, doi: 10.1109/78.258082.

McArdle, N., and G. Paton, 2014, Comparison of spectral enhancement techniques applied to post stack data: 76th Annual International Conference and Exhibition, EAGE, Extended Abstracts, doi: 10.3997/2214-4609 .20141567 . 
McGowran, B., Q. Li, J. Cann, D. Padley, D. M. McKirdy, and S. Shafik, 1997, Biogeographic impact of the Leeuwin Current in southern Australia since the late middle Eocene: Palaeogeography, Palaeoclimatology, Palaeoecology, 136, 19-40, doi: 10.1016/S0031-0182(97)00073-4.

Meldahl, P., R. Heggland, B. Bril, and P. Groot, 2001, Identifying faults and gas chimneys using multiattributes and neural networks: The Leading Edge, 20, 474-482, doi: 10.1190/1.1438976.

Nieminen, A., P. Heinonen, and Y. Neuvo, 1987, A new class of detail-preserving filters for image processing: IEEE Transactions on Pattern Analysis and Machine Intelligence, PAMI-9, 74-90, doi: 10.1109/TPAMI.1987 .4767873 .

Paton, G., and J. Henderson, 2015, Visualization, interpretation and cognitive cybernetics: Interpretation, 3, no. 3, SX41-SX48, doi: 10.1190/INT-2014-0283.1.

Perona, P., and J. Malik, 1990, Scale space and edge detection using anisotropic diffusion: IEEE Transactions on Pattern Analysis and Machine Intelligence, 12, 629-639, doi: 10.1109/34.56205.

Purves, S., and H. Basford, 2011, Visualizing geological structure with subtractive color blending, in K. J. Marfurt, D. Gao, A. Barnes, S. Chopra, A. Corrao, B. Hart, H. James, J. Pacht, and N. C. Rosen, eds., Attributes: New views on seismic imaging - Their use in exploration and production: 31st Annual Gulf Coast Section SEPM Foundation Bob F. Perkins Research Conference.

Sanchez, C. M., 2011, Controls on sedimentary processes and 3D stratigraphic architecture of a mid-Miocene to recent, mixed carbonate-siliciclastic continental margin: Northwest Shelf to Australia: M.S. thesis, The University of Texas at Austin.

Sanchez, C. M., C. S. Fulthrope, and R. J. Steel, 2012, Middle Miocene-Pliocene siliciclastic influx across a carbonate shelf and influence of deltaic sedimentation on shelf construction, Northern Carnarvon Basin, Northwest Shelf of Australia: Basin Research, 24, 664-682, doi: 10.1111/j .1365-2117.2012.00546.x.

Stark, T. J., 2006, Visualization techniques for enhancing stratigraphic inferences from 3D seismic data volumes: First Break, 24, 75-85.

Szafian, P., J. Lowell, A. Eckersley, and T. Kristensen, 2015, Frequency decomposition of broadband seismic data: Challenges and solutions: Presented at the Workshop on Broadband Marine Seismic, EAGE.
USGS, 2004, Landslide types and processes, http://pubs .usgs.gov/fs/2004/3072/fs-2004-3072.html, accessed 26 July 2015.

Vanorio, T., E. Yael, and A. El Husseiny, 2012, Challenges and current advances in the rock physics of carbonate rocks: Presented at the Hedberg Conference on Fundamental Controls on Flow in Carbonates, AAPG.

Wallace, M., W. E. Condilis, A. Powell, J. Redfearn, K. Auld, M. Wiltshire, G. Holdgate, and S. J. Gallagher, 2003, Geological controls on the sonic velocity in the Cenozoic carbonates of the North Carnarvon Basin, North West Shelf, Western Australia: AAPEA Journal, 43, 37-48.

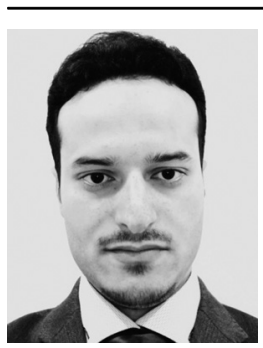

Mohammed Al-Maghlouth received a B.S. in geophysics with first class honors from Curtin University of Technology, Perth, Australia, and an M.S. in petroleum geoscience from Imperial College, London, UK. He works as an exploration geoscientist at Saudi Aramco, where his primary responsibilities are prospect identification and maturation and overseeing the exploration drilling program.

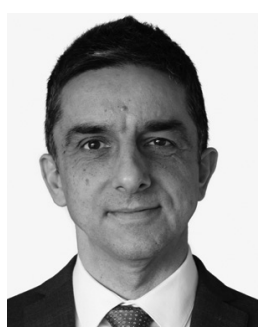

Peter Szafian received an M.S. in geophysics from Eotvos University, Budapest, Hungary, and a Ph.D. in earth sciences from the Vrije Universiteit, Amsterdam, the Netherlands. He works as a principal geoscientist at GeoTeric in London, where his primary responsibilities are workflow development and consultancy related to seismic imaging and attribute analysis.

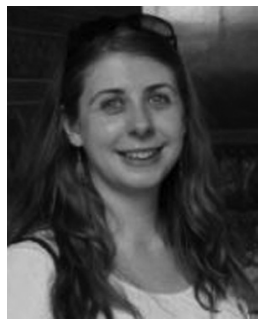

Rebecca Bell received an M.S. from the University of Oxford, UK, and a Ph.D. from the University of Southampton, UK, in marine geophysics. Currently, she is a lecturer in geology and geophysics at Imperial College London, UK, where she studies tectonostratigraphic evolution in a variety of settings using controlled-source seismic methods and drilling data. 